NBER WORKING PAPER SERIES

RISK, AMBIGUITY, AND THE EXERCISE OF EMPLOYEE STOCK OPTIONS
Yehuda Izhakian
David Yermack
Working Paper 19975
http://www.nber.org/papers/w19975

NATIONAL BUREAU OF ECONOMIC RESEARCH

1050 Massachusetts Avenue

Cambridge, MA 02138

March 2014

We appreciate helpful comments by Steven Huddart and Jennifer Carpenter. The views expressed herein are those of the authors and do not necessarily reflect the views of the National Bureau of Economic Research.

NBER working papers are circulated for discussion and comment purposes. They have not been peerreviewed or been subject to the review by the NBER Board of Directors that accompanies official NBER publications.

(C) 2014 by Yehuda Izhakian and David Yermack. All rights reserved. Short sections of text, not to exceed two paragraphs, may be quoted without explicit permission provided that full credit, including (c) notice, is given to the source. 
Risk, Ambiguity, and the Exercise of Employee Stock Options

Yehuda Izhakian and David Yermack

NBER Working Paper No. 19975

March 2014

JEL No. G12,G13,G34,J33

\begin{abstract}
$\underline{\text { ABSTRACT }}$
We investigate the importance of ambiguity, or Knightian uncertainty, in executives' decisions about when to exercise stock options. We develop an empirical estimate of ambiguity and include it in regression models alongside the more traditional measure of risk, equity volatility. We show that each variable has a statistically significant effect on the timing of option exercises, with volatility causing executives to hold their options longer in order to preserve remaining option value, and ambiguity increasing the tendency for executives to exercise early in response to risk aversion. Regression estimates for the volatility and ambiguity variables imply similar magnitudes of economic impact upon the exercise decision, with the volatility variable being about 2.5 times stronger.
\end{abstract}

\author{
Yehuda Izhakian \\ Zicklin College of Business \\ One Bernard Baruch Way \\ New York, NY 10010 \\ yud@stern.nyu.edu \\ David Yermack \\ Stern School of Business \\ New York University \\ 44 West Fourth Street, Suite 9-160 \\ New York, NY 10012 \\ and NBER \\ dyermack@stern.nyu.edu
}




\section{Risk, Ambiguity, and the Exercise of Employee Stock Options}

\section{Introduction}

This paper explores the role of Knightian uncertainty, also known as ambiguity, in executives' decisions about when to exercise their stock options. Our results should help clarify a longstanding division (or ambiguity) in the compensation literature over whether risk is positively or negatively associated with the early exercise of executive options. Two competing hypotheses predict that risk may cause executives to exercise stock options early, due to their impulse to diversify, or alternatively, that risk may cause options holders to delay exercise, since the remaining option value increases when risk is high. Table 1 lists six major studies of employee stock option exercises in recent years, using very large datasets with observations ranging between 1985 and 2009. These studies are decidedly split on whether greater risk, as measured by equity volatility, predicts earlier or later exercise of options.

In our regression model of option exercises, we introduce the concept of ambiguity alongside the more widely used measure of equity volatility, because each of these measures of risk is potentially important to employee option holders. Ambiguity is based upon the concept of Knightian uncertainty, introduced in Knight's (1921) treatise on Risk, Uncertainty, and Profit. Knightian uncertainty refers to conditions under which the set of events that may occur are $a$ priori unknown, and the odds of these possible events are also either not unique or are unknown. Knightian uncertainty is distinctly different than volatility and related measures of financial risk, which typically treat the set of future outcomes (such as the range of future stock prices) as known, with certain probabilities assigned to them and adding to one. The most familiar public 
discussion of Knightian uncertainty probably occurred in 2002, when U.S. Secretary of Defense Donald Rumsfeld drew a distinction between "known unknowns" and "unknown unknowns" when discussing hypothetical chemical weapons held by Iraq.

Previous studies have focused on the theoretical aspect of ambiguity, while not testing their models empirically. In general these studies employ decision models that do not provide separation between risk and ambiguity and between preferences and beliefs. Therefore, they do not provide a straightforward way for measuring ambiguity. ${ }^{1}$ We believe our study is the first to introduce ambiguity into an option pricing model, and we use an empirical method to estimate the impact of ambiguity upon the timing of stock option exercises while controlling for the impact of volatility, the more traditional measure of risk. We find that ambiguity and volatility measure distinctly separate aspects of financial uncertainty, as they have a simple correlation that is weakly positive but not far from zero.

Our analysis provides consistent evidence that both volatility and ambiguity are significantly associated with option exercises, but in opposite directions. Our regression estimates indicate that high ambiguity is associated with earlier option exercises, while high volatility is associated with later exercises. Ambiguity therefore appears to influence exercise policy through the channel more commonly described as risk aversion. The magnitudes of the coefficient estimates for the two variables imply that they operate with very similar economic strength in executives' exercise decisions, with the volatility variable appearing to have about 2.5 times as much influence as the ambiguity variable.

Our results add to a growing literature of papers that fit models of stock option exercise using predictor variables beyond those that appear in the classical binomial or Black-Scholes

\footnotetext{
${ }^{1}$ Earlier literature dealt with this limitation either by calibration (for example, Ju and Miao (2011)) or by attributing the disagreement of professional forecasters to ambiguity (for example, Anderson et al. (2009)).
} 
models. In addition to the papers listed in Table 1, an interesting related paper is Spalt (2013), which studies awards rather than exercises of executive stock options. Like us, the author of that paper uses a framework based on cumulative prospect theory to estimate employees' perceived value of option awards, with the results of the paper hinging upon a transformation of probabilities of future realizations of the underlying stock price such that employees' beliefs deviate from the true distribution. The author finds that firms with high idiosyncratic volatility grant more options to their employees, a result that can be supported by prospect theory but not by classical option pricing models.

The remainder of this paper is organized as follows. Section II presents a theoretical discussion of ambiguity and develops our hypotheses. Section III describes our sample selection and variable definitions, including the estimates of the ambiguity and volatility variables that are central to our investigation. Section IV presents regression analysis of option exercise, and Section V concludes the paper.

\section{Ambiguity}

Many real-life financial decisions involve ambiguity. As a simple example, suppose two urns contain a mixture of black and yellow balls in unknown and possibly different proportions, and you are offered a prize for selecting a yellow ball with only one attempt. The first urn contains

30 balls, and the second urn contains 10. From which urn should you choose to make your selection?

Treating ambiguity analytically can help decision-makers to rank order alternatives such as the two urns in the game above. With employee stock options, the decision above is similar to 
the decision of whether to continue holding an option or to exercise it when the degree of ambiguity changes.

\section{II.1. The decision theoretic model of ambiguity}

Knightian uncertainty has provided the basis for a rich literature in decision theory that begins with Schmeidler (1989) and Gilboa and Schmeidler (1989). These pioneering studies provide axiomatic foundations for modeling decision making under ambiguity, and they suggest that in the presence of ambiguity, an individual's beliefs may take the form of either multiple priors or a single but nonadditive prior. In their model of max-min expected utility with multiple priors, Gilboa and Schmeidler (1989) assert that an ambiguity-averse individual possesses a set of priors and evaluates her ex ante welfare conditional upon the worst prior. The subjective nonadditive probabilities of Gilboa (1987), the Choquet expected utility of Schmeidler (1989) and the cumulative prospect theory of Tversky and Kahneman (1992) suggest that, in the presence of ambiguity, the probabilities that reflect the individual's willingness to bet might not be additive.

Earlier literature on ambiguity focuses mainly on its theoretical aspects, with special attention to the implications of ambiguity for the equity premium. See, for example, Cao et al. (2005), Nau (2006), Epstein and Schneider (2008) and Izhakian and Benninga (2011). Other studies attempt to provide explanations for puzzling asset pricing phenomena by introducing ambiguity into conventional asset pricing models. For example, Pflug and Wozabal (2007) and Boyle et al. (2011) suggest extensions of the mean-variance approach to incorporate ambiguity. Additional papers have developed extensions of the capital asset pricing model that incorporate ambiguity, such as Chen and Epstein (2002), Maccheroni et al. (2009) and Izhakian (2012b). 
We distinguish the concepts of risk and ambiguity by using the theoretical framework of expected utility with uncertain probabilities (EUUP). EUUP, proposed by Izhakian (2012a), is based on Schmeidler's (1989) Choquet expected utility but puts more structure on subjective probabilities (capacities) and adds reference-dependent beliefs. Like Tversky and Kahneman's (1992) cumulative prospect theory, EUUP assumes that investors have a reference point relative to which outcomes are classified as unfavorable (a loss) or as favorable (a gain). Outcomes below than the reference point are considered unfavorable, and higher outcomes are considered favorable. The cumulative probability of unfavorable outcomes plays an important role in estimating the degree of ambiguity. Unlike cumulative prospect theory, EUUP does not assume different attitudes toward risk for losses and for gains (i.e., loss aversion).

EUUP assumes that a random variable is subject to two tiers of uncertainty, one with respect to the value of outcomes, and the other with respect to the probabilities of these outcomes. Each tier of uncertainty is modeled by a separate state space. This structure introduces a complete distinction of risk from ambiguity with regard to both beliefs and preferences. The degree of risk and investors' attitudes toward it are then measured with respect to the first space, while ambiguity and investors' attitudes toward it are measured with respect to the second space. In our approach, the separability of risk and ambiguity represents an assumption. While previous literature (e.g., Schmeidler (1989) and Gilboa and Schmeidler (1989)) makes a considerable contribution to understanding preferences with respect to ambiguity, a complete separation between ambiguity and risk has not yet been derived.

Formally, let $(\Omega, \mathcal{F}, \mathrm{P})$ be a probability space, where $\mathrm{P} \in \mathbb{P}$ is an uncertain (random) probability measure, and the set of probability measures $\mathbb{P}$ is closed and convex. The set $\mathbb{P}$ is equipped with a Borel probability measure, denoted $\chi$, with a bounded support. Given a random 
variable, $X: \Omega \rightarrow \mathbb{R}$ its random mean $\mathrm{E}_{\mathrm{P}}(X)$ and random variance $\operatorname{Var}_{\mathrm{P}}(X)$, conditional upon the random probability measure $\mathrm{P} \in \mathbb{P}$, are denoted by the Greek letters $\mu$ and $\sigma^{2}$, respectively.

Investors have distinct preferences concerning risk and concerning ambiguity. As usual, preferences concerning risk are modeled by a strictly-increasing, continuous and twicedifferentiable utility function $\mathrm{U}: \mathbb{R} \rightarrow \mathbb{R}$, which in our case is normalized to $\mathrm{U}(k)=0$. Risk aversion takes the form of a concave $\mathrm{U}$, risk loving the form of a convex $\mathrm{U}$, and risk neutrality the form of a linear U . Preferences concerning ambiguity are modeled by a strictly-increasing, continuous and twice-differentiable function over probabilities, $\Gamma:[-1,1] \rightarrow \mathrm{R}$, called the outlook function. Similarly to risk, ambiguity aversion takes the form of a concave $\Gamma$, while ambiguity loving takes the form of a convex $\Gamma$, and ambiguity neutrality the form of a linear $\Gamma$. In EUUP, ambiguity aversion occurs when an investor prefers the expectation of an uncertain probability of each outcome over the uncertain probability itself. ${ }^{2}$

Because individuals may interpret random probabilities in nonlinear ways, perceived probabilities in EUUP are nonadditive, meaning that they do not necessarily add to 1. Ambiguity aversion results in a subadditive probability measure, while ambiguity loving results in a superadditive measure. The expected utility of consuming the future risky and ambiguous outcome $X$ of some investment is, therefore, formed by:

$$
\begin{aligned}
\mathrm{V}(\mathrm{X})= & -\int_{-\infty}^{0} \Gamma^{-1}\left(\int_{\mathbb{P}} \Gamma(\mathrm{P}(\mathrm{U}(X) \leq z)) d \chi\right) d z \\
& +\int_{0}^{\infty} \Gamma^{-1}\left(\int_{\mathbb{P}} \Gamma(\mathrm{P}(\mathrm{U}(X) \geq z)) d \chi\right) d z
\end{aligned},
$$

where $\mathrm{U}(k)=0$, is a reference point that distinguishes between unfavorable outcomes (losses) and favorable outcomes (gains). The function, proposed by Izhakian (2012a), is based upon the

\footnotetext{
${ }^{2}$ Recall that risk aversion is exhibited when an investor prefers the expected return of the random return over the random return itself.
} 
functional representation of Wakker (2010) and Kothiyal et al. (2011). This function applies a two-sided Choquet integration to gains and to losses, relative to a reference point $\kappa$. When investors are ambiguity neutral, i.e., $\Gamma$ is linear, Equation (1) collapses to the conventional expected utility.

\section{II.2. Implications of ambiguity for option pricing}

To study the impact of ambiguity on option prices, consider a binomial asset with the outcomes $D$ and $U$ in the bad and the good states of nature, respectively. Assume that the reference point $\kappa$ satisfies $0 \leq \mathrm{E}[X] \leq k$, where $\mathrm{E}[X]$ is the expected outcome taken with respect to the expected

probabilities $\mathrm{E}[\mathrm{P}(x)]=\int_{\mathbb{P}} \mathrm{P}(x) d \chi$. By Equation (1), the value of this asset in terms of expected utility is

$$
\mathrm{V}(X)=\Gamma^{-1}\left(\int_{\mathbb{P}} \Gamma(\mathrm{P}(D)) d \chi\right) \mathrm{U}(D)+\Gamma^{-1}\left(\int_{\mathbb{P}} \Gamma(\mathrm{P}(U)) d \chi\right) \mathrm{U}(U)
$$

To observe the distinct impact of ambiguity and preference concerning it on the asset value, one can take a second Taylor approximation of $\Gamma$ with respect to the uncertain probabilities around the expected probability of each event separately, to obtain

$$
\begin{aligned}
\mathrm{V}(X) \approx \quad & \left(\mathrm{E}[\mathrm{P}(D)]+\frac{1}{2} \frac{\Gamma^{\prime \prime}(\mathrm{E}[\mathrm{P}(D)])}{\Gamma^{\prime}(\mathrm{E}[\mathrm{P}(D)])} \operatorname{Var}[\mathrm{P}(D)]\right) \mathrm{U}(D)+ \\
& \left(\mathrm{E}[\mathrm{P}(U)]+\frac{1}{2} \frac{\Gamma^{\prime \prime}(\mathrm{E}[\mathrm{P}(U)])}{\Gamma^{\prime}(\mathrm{E}[\mathrm{P}(U)])} \operatorname{Var}[\mathrm{P}(U)]\right) \mathrm{U}(U)
\end{aligned} .
$$

Since every probability measure $\mathrm{P} \in \mathbb{P}$ is additive, $\operatorname{Var}[\mathrm{P}(D)]=\operatorname{Var}[\mathrm{P}(U)]$. Using this notion of variance of probabilities, the degree of ambiguity can be measured by

$$
\mho^{2}[X]=4 \operatorname{Var}[\mathrm{P}(U F)]=4 \operatorname{Var}[\mathrm{P}(F V)]
$$


where $\operatorname{Var}[\mathrm{P}(U F)]$ stands for the variance of the cumulative probability of unfavorable events, and $\operatorname{Var}[\mathrm{P}(F V)]$ stands for the variance of the cumulative probability of favorable events, taken with respect to the second order probabilities $\chi$. The measure $\mho^{2}\left(m h o^{2}\right)$ can be used in the general case of random variables with multi states of nature, see Izhakian (2012a). ${ }^{3}$

Ambiguity and aversion to it are modeled in Equation (3) through the investor's perceived probabilities. Consider, for example, the good outcome. The expression

$$
\mathrm{E}[\mathrm{P}(U)]+\frac{1}{2} \frac{\Gamma^{\prime \prime}(\mathrm{E}[\mathrm{P}(U)])}{\Gamma^{\prime}(\mathrm{E}[\mathrm{P}(U)])} \operatorname{Var}[\mathrm{P}(U)]
$$

is the perceived probability of this outcome occurring. This probability is a function of the degree of ambiguity, measured by $\operatorname{Var}[\mathrm{P}(\mathrm{U})]$, and the investors' preferences concerning ambiguity, formed by the coefficient of absolute ambiguity aversion $\frac{\Gamma^{\prime \prime}}{\Gamma^{\prime}}$. Aversion to ambiguity, modeled by a concave $\Gamma$ implies $\frac{\Gamma^{\prime \prime}}{\Gamma^{\prime}}<0$. For an ambiguity-averse investor, a higher aversion to ambiguity or a higher degree of ambiguity result in lower perceived probabilities, which in turn imply lower expected utility.

Consider now a one-period call option on the binomial asset X, with the exercise price $\mathrm{D} \leq \mathrm{K} \leq \mathrm{k} \leq \mathrm{U}$. By Equation (3) the value of this option (in terms of expected utility) is

$$
\mathrm{C}(X) \approx\left(\mathrm{E}[\mathrm{P}(U)]+\frac{1}{8} \frac{\Gamma^{\prime \prime}(\mathrm{E}[\mathrm{P}(U)])}{\Gamma^{\prime}(\mathrm{E}[\mathrm{P}(U)])} \mho^{2}[X]\right) \mathrm{U}(U)
$$

By this equation we can make the following claims:

Claim 1: The option value increases with the risk of the underlying equity.

\footnotetext{
${ }^{3}$ In asset pricing the degree of ambiguity $\mho^{2}$ can be decomposed into systematic and idiosyncratic ambiguity. See Izhakian (2012b).
} 
To see this, assume that the risk of the underling $\mathrm{X}$ increases such that the bad outcome is $D-Z$ and the good outcome is $U+Z$, for some $Z>0$. Clearly, by Equation (5), the value of the call option increases in risk.

Claim 2: The option value decreases with the aversion to ambiguity.

Higher aversion to ambiguity implies a lower $\frac{\Gamma^{\prime \prime}(\mathrm{E}[\mathrm{P}(\mathrm{U})])}{\Gamma^{\prime}(\mathrm{E}[\mathrm{P}(\mathrm{U})])}$, lower perceived probabilities, and therefore a lower value of the option. To see this, take for example an ambiguity preference of the constant absolute ambiguity aversion type. In this case $\frac{\Gamma^{\prime \prime}(E[P(U)])}{\Gamma^{\prime}(E[P(U)])}=-\eta$, where $\eta$ is the coefficient of absolute ambiguity aversion. Higher aversion to ambiguity implies a higher $\eta$ and therefore a lower $-\eta$.

Claim 3: Assuming ambiguity-averse investors, the option value decreases with the ambiguity of the underlying equity.

Since aversion to ambiguity implies a negative $\frac{\Gamma^{\prime \prime}(\mathrm{E}[\mathrm{P}(\mathrm{U})])}{\Gamma^{\prime}(\mathrm{E}[\mathrm{P}(\mathrm{U})])}$, a higher ambiguity of the underlying equity, measured by $\mho^{2}[X]$, implies a lower perceived probabilities (Equation (5)) and therefore a lower value of the option.

\section{II.3. Binomial example}

In this section we illustrate the impact of ambiguity and risk on option prices with a simple numerical example. Consider an underlying equity whose current price is $\$ 1$. In the next period its price can be either $\$ 1.1$ or $\$ 0.9$, i.e., respectively $+10 \%$ or $-10 \%$ returns. Assume an ambiguity-averse investor of a constant absolute ambiguity aversion type with coefficient of 
ambiguity aversion $\eta=-\frac{\Gamma^{\prime \prime}}{\Gamma^{\prime}}=2$. For simplicity, assume that the investor is risk neutral and has a reference point $\mathrm{k}=1$. Recall that the reference point distinguishes between losses and gains.

Let a one period call option have an exercise price $\mathrm{k}=1$ and assume that the probabilities of each, the bad outcome and the good outcome, are exactly 50\%, which means that no ambiguity is present. In this case, the variance of the probability of the favorable outcome is 0 and therefore, by substituting into equation (5), the value of the call option is is $C(X)=0.5 \times$ $1.1=0.55$. If the risk of the underlying equity increases such that the bad and the good outcomes are, respectively, $\$ 0.8$ and $\$ 1.2$, then the value of the call option increases to $\mathrm{C}(\mathrm{X})=$ $0.5 \times 1.2=0.6$

Assume now that the probabilities of the future outcomes of the underlying equity are ambiguous such that the outcomes are distributed either $(0.4,0.6)$ or $(0.6,0.4)$ with equal likelihood. In this case, the expected probability of the favorable outcome is $\mathrm{E}[\mathrm{P}(U)]=0.5 \times$ $0.4+0.5 \times 0.6=0.5$ and its variance is $\operatorname{VAR}[\mathrm{P}(U)]=0.5(0.4-0.5)^{2}+0.5(0.6-0.5)^{2}=$ 0.01, implying that the degree of ambiguity is $\mho^{2}=4 \times 0.01=0.04$. Substituting into Equation (5), the value of the call option (in terms of expected utility) is $\mathrm{C}(\mathrm{X})=\left(0.5-\frac{1}{8} \times 2 \times\right.$ 0.04) $1.1=0.539$. For an investor with higher aversion to ambiguity, say $\eta=4$, the value of the option (in terms of expected utility) drops to $C(X)=\left(0.5-\frac{1}{8} \times 4 \times 0.04\right) 1.1=0.528$. If the degree of ambiguity of the underlying equity increases such that the future outcomes are distributed either either $(0.3,0.7)$ or $(0.7,0.3)$, then the expected probability of the favorable outcome remains unchanged $\mathrm{E}[\mathrm{P}(\mathrm{U})]=0.5 \times 0.3+0.5 \times 0.7=0.5$ but the variance of its probability increases to $\operatorname{VAR}[\mathrm{P}(\mathrm{U})]=0.5(0.3-0.5)^{2}+0.5(0.7-0.5)^{2}=0.04$, implying a 
degree pf ambiguity of $\mho^{2}=4 \times 0.04=0.16$. Substituting into Equation (5), the value of the call option drops to $C(X)=\left(0.5-\frac{1}{8} \times 2 \times 0.16\right) 1.1=0.484$.

\section{II.4. Hypotheses}

We turn now to developing our hypotheses based upon the claims of Section II.2. In particular, Claim 1 proposes that a higher volatility of the underlying equity implies a higher value of the option. On the other hand, Claim 3 proposes that a higher ambiguity of the underlying equity implies a lower value of the option. These claims suggest that the risk and the ambiguity associated with the underlying equity have opposite effects on the incentive that employees have to exercise their vested options.

Hypothesis H1: When the expected risk associated with the underlying asset is high, employees tend to hold their options rather than exercise them, and vice versa.

At each interval of time, an option holder has to decide whether to exercise his vested options or keep the option alive and defer the decision to the next period. His choice is based upon the future expected value of the option relative to its current value, assuming that the market price of the underlying equity reflects its value in terms of expected utility. If the option holder expects the volatility of the underlying equity to be high in the next month, then he anticipates a higher value of option in the next month. Therefore, to maximize his expected utility, he would prefer to continue holding the option and leave it unexercised.

Hypothesis H2: When the expected ambiguity associated with the underlying asset is high, employees tend to exercise their options rather than hold them, and vice versa. 
Claim 3 demonstrates that ambiguity and option value are negatively related. This means that if the ambiguity of the underlying asset is expected to be high, the value of an option on this equity is expected to be low.

\section{Data description}

\section{III.1. Sample selection}

We estimate the relation between ambiguity and the timing of option exercises using a sample from Table 2 of the Thomson Reuters Insiders Data database. After a process of data cleaning and filtering described below, we analyze 63,244 option exercises by 19,192 employees in 3,006 individual firms. Our unit of observation for regression analysis is an award-month, and we include each month for which an option is vested (or exercisable) and not yet fully exercised, 2,142,732 observations in all.

To construct our sample, we begin with a download of 5,322,257 records from the entire Thomson Reuters database from January 1996 to December 2013, with each record representing either an award or an exercise of a given grant to a given employee in a specific firm. Each unique grant is identified using the firm identifier, security identifier, person identifier, vesting date and termination date. When one of these descriptors is missing, we attempt to complete it using information from other records of the same grant. After this data cleaning, we drop all records missing one of the following descriptors: vesting date, expiration date, number of options, or exercise price. In addition, we drop all records that we cannot match with identifiers to the CRSP stock price database. This filtering leaves us with 3,862,174 records. After dropping duplicate records, 3,552,491 are left. 
Next, we aggregate the exercise and cancellation transactions related to each grant on a monthly basis. All grants that are never exercised are dropped (many may have expired out of the money, some are still active today, and others may have been exercised after the option holder left the company and had no reporting obligation). We identify 107,930 unique option grants for which we have both award and exercise data. For each month for each of these grants, we construct a cumulative total of the number of vested options that have not yet been exercised. When the database reports an exercise quantity equal to or exceeding the number of options held, we consider the observation to represent an exercise of all of the remaining options and drop all future months. Using this method, we are left with a sample of 4,007,854 monthly observations for the 107,930 unique grants, representing the period between the vesting date and the exercise date for each grant.

We reduce this sample of 4,007,854 observations to a sample suitable for regression analysis after calculating the necessary independent variables for each observation. In general we require 12 months of stock price history to construct measures of expected volatility and expected ambiguity from daily and intraday returns as described below. This was possible for 2,586,265 observations. Finally, we drop all out-of-the-money options, based upon the closing price at the end of the prior month. This leaves us with 2,142,732 monthly observations during which employees could have exercised their options. Our main dependent variable is the percentage of options exercised by the option holder in a particular month, equal to the number exercised over the number held at the start of the month. Because option exercises occur only infrequently, for most months this variable equals zero. This property of the data suggests that a Tobit estimation would be most appropriate, but it was not possible for us to fit a Tobit model with fixed effects and clustered standard errors. Therefore, we a general linear mixed model 
(GLMM) with clustering and fixed effects in the regression analysis below. In unreported sensitivity tests, we find little difference between our reported GLMM estimates and Tobit estimates without fixed effects and clustered standard errors.

\section{III.2. Estimating expected ambiguity}

To estimate the degree of ambiguity of a given underlying asset from trading data, one must first elicit the possible probabilities of unfavorable outcomes (returns). To do so, one must make assumptions about the nature of the probability distribution of returns and the investors' reference point. We define the reference point to be the risk-free rate of return, denoted $r_{f}$. That is, any return lower than $r_{f}$ is considered an unfavorable and any return greater than $r_{f}$ is considered favorable (alternatively, one could take 0 to be the reference point). In addition we assume that returns on assets are log-normally distributed; therefore, the degree of ambiguity of the return $r_{j}$ on the underlying asset can be measured by

$$
\mho^{2}\left[r_{j}\right]=4 \operatorname{Var}\left[\Phi\left(r_{f}, \mu_{j}, \sigma_{j}\right)\right]
$$

where $\Phi\left(r_{f}, \mu_{j}, \sigma_{j}\right)=\frac{1}{\sqrt{2 \pi \sigma_{j}^{2}}} \int_{-\infty}^{r_{f}} e^{-\frac{\left(r_{j}-\mu_{j}\right)^{2}}{2 \sigma_{j}^{2}}} d r_{j}$ is the cumulative probability of unfavorable outcome and $\mu_{j}$ and $\sigma_{j}^{2}$ are the random mean and the random variance of the return on the underlying equity, respectively.

We employ the empirical method developed by Brenner and Izhakian $(2011,2012)$ to estimate the degree of ambiguity using intraday stock trading data from the TAQ database. We compute the degree of ambiguity given in Equation (7), for each stock and for each month, by applying the following procedure. We sample the price of the stock every five minutes starting from 9:30 until 16:00. In cases where there is no trade at a specific time interval, we take the 
volume-weighted average of the closest trading price. Using these prices we compute fiveminute returns, 78 times for each day. Note that this procedure implies that we ignore returns between each closing price and opening price on the following day, thereby eliminating the impact of overnight price changes and dividend distributions. For each stock, we drop all trading days that do not have at least 15 quotes representing different five minute time intervals, and we drop all trading months that do not have at least 15 days that satisfy this condition. Observations with extreme price changes (minus or plus 20 percent log returns) within five minutes are also dropped.

For a given stock, for each day we compute the mean and variance of five-minute returns applying the adjustment for non-synchronous trading proposed by Scholes and Williams (1977) and a correction for heteroscedasticity. Then, by the assumption that the intraday returns are lognormally distributed, we compute for each day the probability of an unfavorable outcome (loss) using the cumulative normal probability distribution. For each month, there are 20 to 22 different loss-probabilities. From these loss-probabilities we compute the standard deviation of the probability of loss to obtain the degree of ambiguity, $\mho$, for an individual stock in a given month. The average ambiguity $\mho$ (over firms) is positively skewed. To adjust for skewness, we examine the natural logarithm of $\mho_{j, t}$. Finally, we assume that investors form an expectation about future ambiguity by taking into account the evolution of a given stock's ambiguity over time. Regression analysis indicates that the average autocorrelations (over firms) of $\ln \left(\mho_{\mathrm{j}, \mathrm{t}}\right)$ decays beyond lag 9 , suggesting that $\ln \left(\mho_{\mathrm{j}, \mathrm{t}}\right)$ follows a nine-order autoregressive process. Based upon the Akaike information criterion (AIC), for each equity $\mathrm{j}$, we estimate the conditional ambiguity using an $\mathrm{AR}(7)$ with one period autocorrelated residuals model of the 
time-series of the natural logarithm of ambiguity. For every month $t$ we perform the following time-series regression for each equity $j$ :

$$
\ln \left(\mho_{j, t}\right)=\phi_{0}+\phi_{1} \ln \left(\mho_{j, t-1}\right)+\cdots+\phi_{7} \ln \left(\mho_{j, t-7}\right)+\epsilon_{j, t}+\theta_{1} \epsilon_{j, t-1} .
$$

Then we estimate the expected ambiguity by

$$
\left.\mho_{j, t}^{E}=\operatorname{Exp}\left(\widehat{\ln \left(\mho_{\jmath, t}\right.}\right)+\frac{1}{2} V\left(\epsilon_{j, t}\right)\right)
$$

where $\overline{\ln \left(\mho_{J, t}\right)}$ is estimated using coefficients estimated by Equation (7).

\section{III.3. Estimating expected volatility}

Along with ambiguity, volatility serves as the most important explanatory variable in our analysis. We compute volatility with standard methods, using daily log returns adjusted for dividends obtained from the CRSP database. For each individual stock in a given month we calculate the standard deviation, $\sigma$, of the stock's daily returns over that month, again applying the Scholes and Williams (1977) correction for non-synchronous trading and a correction for heteroscedasticity. ${ }^{4}$ As with ambituity, the average volatility measures $\sigma$ (over firms) are also positively skewed. To adjust for skewness we examine the natural logarithm of $\sigma_{\mathrm{j}, \mathrm{t}}$. Again we assume that investors form an expectation about future volatility based upon its evolution over time for a given stock. The average autocorrelations (over firms) of $\ln \left(\sigma_{\mathrm{j}, \mathrm{t}}\right)$ decay beyond lag 6 , suggesting that $\ln \left(\sigma_{\mathrm{j}, \mathrm{t}}\right)$ follows a six-order autoregressive process. Examining the cross correlations between the volatility $\sigma_{\mathrm{j}, \mathrm{t}}$ of equity and its ambiguity in lags $\mho_{\mathrm{j}, \mathrm{t}-1}, \ldots, \mho_{\mathrm{j}, \mathrm{t}-3}$, suggests that, on average, the ambiguity the preceding three months has a significant impact on volatility. Based upon the AIC, for each equity in every month we estimate conditional volatility by AR(6) with two periods autocorrelated residuals model of the time-series of the natural logarithm of

\footnotetext{
${ }^{4}$ See, for example, French, Schwert and Stambaugh (1987).
} 
volatility. Similar to the procedure applied to ambiguity, for every month $t$ we perform the following time-series regression for each equity:

$$
\ln \left(\sigma_{j}\right)=\phi_{0}+\phi_{1} \ln \left(\sigma_{j, t-1}\right)+\cdots+\phi_{6} \ln \left(\sigma_{j, t-6}\right)+\epsilon_{j, t}+\theta_{1} \epsilon_{j, t-1}+\theta_{2} \epsilon_{j, t-2},
$$

and we then estimate the expected volatility by

$$
\left.\sigma_{j, t}^{E}=\operatorname{Exp}\left(\widehat{\ln \left(\sigma_{\jmath, t}\right.}\right)+\frac{1}{2} V\left(\epsilon_{j, t}\right)\right)
$$

where $\widehat{\ln \left(\sigma_{J, t}\right)}$ is estimated using coefficients estimated by Equation (9).

\section{III.3. Other explanatory variables}

In addition to expected ambiguity and expected volatility, our models of option exercises include a number of standard control variables, many of them based on the prior studies listed in Table 1. We include two indicators related to behavioral finance predictions. One indicator equals one during the vesting month, representing the first month in which a given option award can be exercised, and we expect this to have a positive association with the probability of exercise. The other indicator equals one if the stock hits a 12-month high during the prior month, and we also expect this variable to have a positive association with the probability of exercise. The $\log$ of remaining option life (measured as one plus the number of months to expiration) should exhibit a negative relation with the probability of exercise, based on standard comparative statics of option value with respect to time, while the dividend yield of the underlying stock should exhibit a positive relation for the same reason. Following Carpenter, Stanton, and Wallace (2013), we multiply the dividend yield times an indicator that equals one if a dividend is payable in the current month. We include the log of the ratio of prior month-end stock price divided by the option exercise price to capture the depth in-the-money of each option award, and we expect this variable to exhibit a positive association with the probability of exercise. In certain regressions 
we use the change in ambiguity and change in volatility as explanatory variables, and these are calculated as the log of the ratio of the current month's value over the prior month's value.

Table 2 presents summary statistics for the key variables used in the paper, and Table 3 presents a correlation matrix for these variables. The two measures of risk, expected volatility and expected ambiguity, are only weakly related to one another, with an estimated correlation of 0.186. This suggests that the two variables capture economically distinct aspects of financial uncertainty.

\section{Empirical results}

Our regression analysis of how risk impacts executives stock option exercises appears in Table 4. As described above, the sample for analysis includes more than 2.14 million award-month observations in which an executive holds vested, in-the-money options at the start of the month and faces a decision of whether to exercise the option or continue it for another month. The dependent variable in all models is the percentage of an award that is exercised in a given month. All models include standard errors clustered by person, firm, month, and year in order to reflect the lack of independence of multiple observations within executives and within periods of time.

The first two columns of Table 4 show estimates for very basic models with only an intercept and the volatility variable, in the first column, and an intercept and the ambiguity variable, in the second column. Both risk variables appear in a model with an intercept in the third column, and their estimates change little when they are included in the same regression alongside one another. The volatility variable has a negative and significant estimate of approximately -0.15 , while the ambiguity variable has a positive and significant estimate of approximately +0.02 . Moving from left to right in Table 4, we introduce control variables as 
described above and fixed effects for years, persons, and firms. Finally, in the right column of Table 4, we show estimates for the most general model, with all control variables and fixed effects included. Both the volatility and ambiguity variables have significant estimates in every column except one, and they remain relatively unchanged when control variables are added.

Our results imply that risk impacts the option exercise decision in a multi-faceted way, as we find that the volatility and ambiguity variables influence exercises in opposite directions. Our negative and significant estimates for the volatility variable are similar to those found in the recent study by Carpenter, Stanton, and Wallace (2013), the only one of the six papers listed in Table 1 that finds this pattern unambiguously. The Carpenter et al. study appears to have several advantages compared to the others in the table, including a much larger sample over a far longer time period, as well as a more sophisticated estimation method. However, none of the papers considers measures of uncertainty other than the traditional volatility variable, and one of the contributions of our paper appears to be our illustration that different types of uncertainty impact financial decisions sometimes in opposing directions.

To assess the economic significance of the two variables' estimates, we multiply the coefficients in the right column of Table 4 by the standard deviation of each variable as shown in Table 2. The product represents the impact on the exercise decision of a one standard deviation change of each variable. For the volatility variable the relevant calculation is $0.2353 \times$ 0.0078 or about $0.18 \%$, and for the ambiguity variable the calculation is $0.0141 \times 0.0522$, or about $0.07 \%$, implying that the equity volatility variable as about two and a half times stronger influence upon executives' exercise decisions. The unconditional mean of the dependent variable, as shown in Table 2 , is about $2.54 \%$. The two uncertainty variables therefore appear to 
have meaningful, but somewhat modest, impact on executives' month-to-month decisions about whether to exercise their stock options.

Other estimates for variables in Table 4 follow the expected pattern found in other papers. Managers are significantly more likely to exercise their stock options soon after the underlying shares reach a 12-month high, and also in the first month after vesting. While the former result seems to be rooted in behavioral finance, the latter may be an artifact of certain executives planning to change jobs but waiting until their options vest and can be liquidated. We find that options are more likely to be exercised when they are deep in-the-money, when large dividends are payable in the current month, and when the time to expiration grows shorter. All three of these results square with standard comparative statics predictions.

In tables 5 and 6 we present a series of robustness tests to show the consistency of our estimates for the two uncertainty variables. Table 5 displays estimates for regressions with the same specification as the right column of Table 4, in which we include the full range of control variables and fixed effects, alongside three alternative specifications of the volatility and ambiguity variables. We tabulate only the intercept and two uncertainty variables' coefficients in order to save space and highlight the important results. In the first column of Table 5, we reproduce the estimates from the right column of Table 4 for comparison purposes. In the second column of the table, the two uncertainty variables are measured one month earlier, and in the third column, they are measured with two months' lag. Finally, in the right column we take the first difference of each uncertainty variable, equal to the value at the close of the immediately preceding month, minus the value one month earlier. In all four columns of Table 5, the estimates for the uncertainty variables have the same sign, significance, and approximate 
magnitude, although the coefficients are noticeably closer to zero in the right column when we use the first-difference specification.

In Table 6, we continue our robustness tests by fitting our regression model over certain subsets of observations. In the first column, we look at observations for chief executive officers only, according to their job titles reported in the Thomson Reuters database. These option exercises comprise about $16 \%$ of the overall sample. In the center column, we estimate our regression for those observations in the top quartile of the volatility variable, and in the right column, we use those observations that lie in the top $25 \%$ of ambiguity. All models contain the full range of control variables and fixed effects used in the preceding table. Once again we find a high degree of similarity for the uncertainty variables' coefficient estimates, as each variable retains its sign, significance, and approximate magnitude within each of these subsamples of observations.

\section{Conclusion}

We investigate the importance of ambiguity, or Knightian uncertainty, in executives' decisions about when to exercise stock options. The impact of risk on the timing of option exercise has motivated several prior studies which have failed to reach a conclusion about whether the relation is positive or negative. Our contribution involves the introduction of a second measure of uncertainty, ambiguity, alongside the more traditional measure of volatility. The empirical estimates of these two quantities exhibit only a modest correlation, and both turn out to be important. We show that each variable has a statistically significant effect on the timing of option exercises, with volatility causing executives to hold their options longer in order to preserve remaining option value, and ambiguity increasing the tendency for executives to 
exercise early in response to risk aversion. Regression estimates for volatility and ambiguity variables imply very similar magnitudes of economic impact upon the exercise decision, with the volatility variable appearing to impact about 2.5 times more strongly than the ambiguity variable. 


\section{References}

Anderson, E. W., E. Ghysels, and J. L. Juergens (2009) "The Impact of Risk and Uncertainty on Expected Returns," Journal of Financial Economics 94, 233-263.

Armstrong, C., A. D. Jagolinzer, and D. F. Larcker (2007) "Timing of Employee Stock Option Exercises and the Cost of Stock Option Grants," Stanford University working paper, available at www.ssrn.com/abstract $=905280$.

Bettis, J., J. Bizjak, and M. Lemmon (2005) "Exercise Behavior, Valuation, and the Incentive Effects of Employee Stock Options," Journal of Financial Economics 76, 445-470.

Boyle, P., L. Garlappi, R. Uppal, and T. Wang (2011) "Keynes Meets Markowitz: The Tradeoff Between Familiarity and Diversification," Management Science 57, 1-20.

Brenner, M., and Y. Izhakian (2011) "Asset Prices and Ambiguity: Empirical Evidence," New York University working paper, available at www.ssrn.com/abstract=2284649.

Brenner, M., and Y. Izhakian (2012) "Pricing Systematic Ambiguity in Capital Markets," New York University working paper, available at www.ssrn.com/abstract=2119040.

Cao, H. H., T. Wang, and H. Zhang (2005) "Model Uncertainty, Limited Market Participation, and Asset Prices," Review of Financial Studies 18, 1219-1251.

Carpenter, J., R. Stanton, and N. Wallace (2013) "The Importance of Behavioral Factors in the Exercise of Employee Stock Options," New York University working paper, available at people.stern.nyu.edu/jcarpen0/pdfs/CarpenterStantonWallace2013.pdf.

Chen, Z., and L. Epstein (2002) "Ambiguity, Risk, and Asset Returns in Continuous Time," Econometrica 70, 1403-1443.

Epstein, L. G., and M. Schneider (2008) "Ambiguity, Information Quality, and Asset Pricing," Journal of Finance 63, 197-228.

French, K. R., G. W. Schwert, and R. F. Stambaugh (1987) "Expected stock returns and volatility," Journal of Financial Economics, Vol. 19, No. 1, pp. 3-29.

Gilboa, I. (1987) "Expected Utility with Purely Subjective Non-Additive Probabilities," Journal of Mathematical Economics 16, 65-88.

Gilboa, I., and D. Schmeidler (1989) "Maxmin Expected Utility with Non-Unique Prior," Journal of Mathematical Economics 18, 141-153.

Hemmer, T., S. Matsunaga, and T. Shevlin (1996) "The Influence of Risk Diversification on the Early Exercise of Employee Stock Options by Executive Officers," Journal of Accounting and Economics 21, 45-68. 
Huddart, S., and M. Lang (1996) "Employee Stock Option Exercises: An Empirical Analysis," Journal of Accounting and Economics 21, 5-43.

Izhakian, Y. (2012a) "A Theoretical Foundation of Ambiguity Measurement," New York University working paper, available at people.stern.nyu.edu/yizhakia/papers/ambgmsr.pdf.

Izhakian, Y. (2012b) "Capital Asset Pricing under Ambiguity," New York University working paper, available at www.ssrn.com/abstract=2007815.

Izhakian, Y., and S. Benninga (2011) "The Uncertainty Premium in an Ambiguous Economy," Quarterly Journal of Finance 1, 323-354.

Ju, N., and J. Miao (2012) "Ambiguity, Learning, and Asset Returns," Econometrica 80, 559591.

Klein, D., and E. Maug (2011) "How Do Executives Exercise Their Stock Options?" University of Mannheim working paper, available at ssrn.com/abstract=1342316.

Knight, F. (1921) Risk, Uncertainty, and Profit (Boston: Houghton Mifflin).

Kothiyal, A., V. Spinu, and P. P.Wakker (2011) "Prospect Theory for Continuous Distributions: a Preference Foundation," Journal of Risk and Uncertainty 42, 195-210.

Maccheroni, F., M. Marinacci, A. Rustichini, and M. Taboga (2009) "Portfolio Selection with Monotone Mean-Variance Preferences," Mathematical Finance 19, 487-521.

Nau, R. F. (2006) "Uncertainty Aversion with Second-Order Utilities and Probabilities," Management Science 52, 136-145.

Pug, G., and D. Wozabal (2007) "Ambiguity in Portfolio Selection," Quantitative Finance 7, 435-442.

Schmeidler, D. (1989) "Subjective Probability and Expected Utility without Additivity," Econometrica 57, 571-587.

Scholes, M., and J. Williams (1977) "Estimating Betas from Nonsynchronous Data," Journal of Financial Economics 5, 309-327.

Spalt, O. (2013) "Probability Weighting and Executive Stock Options," Journal of Financial and Quantitative Analysis 48, 1085-1118.

Wakker, P. (2010) Prospect Theory: For Risk and Ambiguity (Cambridge, UK: Cambridge University Press). 


\section{Table 1}

\section{Previous studies of risk and executive stock option exercises}

The table shows six previous studies of executive stock option exercises, with information about the sample period, sample size, measurement of risk, and the estimated impact of risk upon early option exercise.

\begin{tabular}{|c|c|c|c|c|c|}
\hline Study & $\begin{array}{l}\text { Sample } \\
\text { period }\end{array}$ & Sample size & $\begin{array}{l}\text { Measurement of } \\
\text { volatility }\end{array}$ & $\begin{array}{l}\text { Impact of risk on } \\
\text { early exercise }\end{array}$ & Remarks \\
\hline $\begin{array}{l}\text { Huddart \& } \\
\text { Lang (1994) }\end{array}$ & $\begin{array}{l}\text { c. } 1985- \\
1995\end{array}$ & $\begin{array}{l}85,853 \text { exercises by } \\
58,316 \text { employees (all } \\
\text { levels) at } 8 \text { companies }\end{array}$ & $\begin{array}{l}\text { Daily stock returns } \\
\text { over one year prior to } \\
\text { exercise month }\end{array}$ & Mixed & $\begin{array}{l}\text { Estimates vary across companies } \\
\text { and job ranks and are sensitive to } \\
\text { estimation method }\end{array}$ \\
\hline $\begin{array}{l}\text { Hemmer, } \\
\text { Matsunaga \& } \\
\text { Shevlin (1996) }\end{array}$ & 1990 & $\begin{array}{l}110 \text { exercises by } 74 \\
\text { officers and directors at } \\
65 \text { firms }\end{array}$ & $\begin{array}{l}\text { Monthly stock returns } \\
\text { over five years prior } \\
\text { to } 1990\end{array}$ & Positive & $\begin{array}{l}\text { Volatility is scaled by Black- } \\
\text { Scholes hedge ratio }\end{array}$ \\
\hline $\begin{array}{l}\text { Bettis, Bizjak } \\
\text { \& Lemmon } \\
(2005)\end{array}$ & $\begin{array}{l}1996- \\
2002\end{array}$ & $\begin{array}{l}\text { 141,020 exercises by } \\
\text { officers and directors at } \\
3,966 \text { companies }\end{array}$ & $\begin{array}{l}\text { Monthly stock returns } \\
\text { over three years prior } \\
\text { to exercise date }\end{array}$ & Positive & \\
\hline $\begin{array}{l}\text { Armstrong, } \\
\text { Jagolinzer \& } \\
\text { Larcker (2007) }\end{array}$ & $\begin{array}{l}\text { c. } 1995- \\
2005\end{array}$ & $\begin{array}{l}17,570 \text { exercises by } \\
15,409 \text { employees (all } \\
\text { levels) at } 10 \text { firms }\end{array}$ & $\begin{array}{l}\text { Daily stock returns } \\
\text { over one year prior to } \\
\text { exercise day }\end{array}$ & Not significant & \\
\hline $\begin{array}{l}\text { Klein \& Maug } \\
\text { (2011) }\end{array}$ & $\begin{array}{l}1996- \\
2008\end{array}$ & $\begin{array}{l}23,646 \text { exercises by } \\
13,948 \text { officers and } \\
\text { directors at } 2,008 \text { firms }\end{array}$ & $\begin{array}{l}\text { Weekly stock returns } \\
\text { over one year prior to } \\
\text { vesting date }\end{array}$ & $\begin{array}{l}\text { "Weak but } \\
\text { positive" }\end{array}$ & $\begin{array}{l}\text { Estimates are significant only in } \\
\text { some models }\end{array}$ \\
\hline $\begin{array}{l}\text { Carpenter, } \\
\text { Stanton \& } \\
\text { Wallace (2013) }\end{array}$ & $\begin{array}{l}1981- \\
2009\end{array}$ & $\begin{array}{l}687,594 \text { exercises by } \\
419,822 \text { employees at } \\
102 \text { firms }\end{array}$ & $\begin{array}{l}\text { Daily stock returns } \\
\text { over } 66 \text { days prior to } \\
\text { grant date }\end{array}$ & Negative & $\begin{array}{l}\text { Uses computationally intensive } \\
\text { GMM estimation }\end{array}$ \\
\hline
\end{tabular}




\section{Table 2}

\section{Descriptive statistics}

The table shows descriptive statistics for the key dependent and explanatory variables in the regression analysis of option exercise timing. The sample includes 2.14 million monthly observations associated with 63,244 option grants that are exercised by 19,192 employees in 3,006 individual firms between 1996 and 2013, using records from the Thomson Reuters Insiders Data file. For a given option award, the percentage of options exercised is the number exercised in a given month divided by the number of vested options held at the start of the month. Expected volatility, based on CRSP daily stock price records, and expected ambiguity, based on TAQ intra-day stock price records, are calculated according to procedures described in the text.

\begin{tabular}{|c|c|c|c|c|c|c|}
\hline Variable & Observations & Mean & Std. Dev. & Minimum & Median & Maximum \\
\hline Percentage of options exercised & $2,142,732$ & 0.0254 & 0.1532 & 0 & 0 & 1 \\
\hline Expected volatility & $2,142,732$ & 0.0176 & 0.0078 & 0.0004 & 0.0161 & 0.1950 \\
\hline Expected ambiguity & $2,142,732$ & 0.4954 & 0.0522 & 0.1129 & 0.4970 & 1.5159 \\
\hline Vesting month indicator & $2,142,732$ & 0.0191 & 0.1369 & 0 & 0 & 1 \\
\hline $\log (1+$ months to expiration $)$ & $2,142,732$ & 7.2887 & 0.8202 & 0.6931 & 7.5256 & 9.3357 \\
\hline 12-month high price indicator & $2,142,732$ & 0.0568 & 0.2315 & 0 & 0 & 1 \\
\hline Dividend yield & $2,142,732$ & 0.0002 & 0.0020 & 0 & 0 & 0.0954 \\
\hline $\begin{array}{r}\times \text { dividend month indicator } \\
\text { Log (stock price / exercise price) }\end{array}$ & $2,142,732$ & 0.8753 & 0.7505 & 0.0000 & 0.7177 & 14.1998 \\
\hline
\end{tabular}




\section{Table 3}

\section{Correlation matrix}

The table displays simple correlations between the key dependent and explanatory variables. The sample includes 2.14 million monthly observations associated with 63,244 option grants that are exercised by 19,192 employees in 3,006 individual firms between 1996 and 2013, using records from the Thomson Reuters Insiders Data file. For a given option award, the percentage of options exercised is the number exercised in a given month divided by the number of vested options held at the start of the month. Expected volatility, based on CRSP daily stock price records, and expected ambiguity, based on TAQ intra-day stock price records, are calculated according to procedures described in the text. All of the correlation estimates in the table are statistically significant below the 0.0001 probability level.

\begin{tabular}{|c|c|c|c|c|c|c|c|}
\hline & $\begin{array}{r}\text { Percentage } \\
\text { of options } \\
\text { exercised }\end{array}$ & $\begin{array}{l}\text { Expected } \\
\text { volatility }\end{array}$ & $\begin{array}{l}\text { Expected } \\
\text { ambiguity }\end{array}$ & $\begin{array}{r}\text { Vesting } \\
\text { month } \\
\text { indicator }\end{array}$ & $\begin{array}{r}\log \\
(1+\text { months } \\
\text { to expiration })\end{array}$ & $\begin{array}{l}\text { 12-month } \\
\text { high price } \\
\text { indicator }\end{array}$ & $\begin{array}{r}\text { Dividend } \\
\text { yield } \\
\times \text { dividend } \\
\text { month }\end{array}$ \\
\hline $\begin{array}{l}\text { Expected } \\
\text { volatility }\end{array}$ & -0.0068 & & & & & & \\
\hline $\begin{array}{l}\text { Expected } \\
\text { ambiguity }\end{array}$ & 0.0056 & 0.1855 & & & & & \\
\hline $\begin{array}{l}\text { Vesting month } \\
\text { indicator }\end{array}$ & 0.0385 & 0.0140 & 0.0108 & & & & \\
\hline $\begin{array}{l}\log (1+\text { months to } \\
\text { expiration })\end{array}$ & -0.1146 & 0.0414 & 0.0256 & 0.0837 & & & \\
\hline $\begin{array}{l}\text { 12-month high } \\
\text { price indicator }\end{array}$ & 0.0065 & -0.0261 & 0.0014 & 0.0077 & 0.0090 & & \\
\hline $\begin{array}{r}\text { Dividend yield } \\
\times \text { dividend month }\end{array}$ & 0.0053 & -0.0257 & -0.0113 & 0.0089 & -0.0073 & 0.0001 & \\
\hline $\begin{array}{l}\text { Log (stock price } \\
\text { / exercise price) }\end{array}$ & 0.0206 & 0.1441 & 0.0795 & -0.0116 & -0.0675 & 0.0483 & -0.0150 \\
\hline
\end{tabular}




\section{Table 4}

\section{Regression estimates of option exercise timing}

Generalized linear mixed model regression estimates of the percentage of an option award that is exercised in the current month. The sample includes 2.14 million monthly observations associated with 63,244 option grants that are exercised by 19,192 employees in 3,006 individual firms between 1996 and 2013, using records from the Thomson Reuters Insiders Data file. For a given option award, the percentage of options exercised is the number exercised in a given month divided by the number of vested options held at the start of the month. Expected volatility, based on CRSP daily stock price records, and expected ambiguity, based on TAQ intra-day stock price records, are calculated according to procedures described in the text. $t$-statistics clustered by person, firm, month and year appear in parentheses below each coefficient estimate. 


\begin{tabular}{|c|c|c|c|c|c|c|c|c|}
\hline Intercept & $\begin{array}{r}0.0278 \\
(107.67)\end{array}$ & $\begin{array}{l}0.0173 \\
(17.33)\end{array}$ & $\begin{array}{r}0.0179 \\
(17.92)\end{array}$ & $\begin{array}{r}0.1722 \\
(128.21)\end{array}$ & $\begin{array}{l}0.1715 \\
(46.14)\end{array}$ & $\begin{array}{r}0.2221 \\
(124.37)\end{array}$ & $\begin{array}{r}0.2643 \\
(160.95)\end{array}$ & $\begin{array}{r}0.2646 \\
(160.88)\end{array}$ \\
\hline Expected volatility & $\begin{array}{r}-0.1319 \\
(-9.88)\end{array}$ & & $\begin{array}{l}-0.1576 \\
(-11.60)\end{array}$ & $\begin{array}{r}-0.1110 \\
(-8.14)\end{array}$ & $\begin{array}{r}-0.0006 \\
(-0.14)\end{array}$ & $\begin{array}{l}-0.4311 \\
(-22.13)\end{array}$ & $\begin{array}{l}-0.2374 \\
(-12.36)\end{array}$ & $\begin{array}{l}-0.2353 \\
(-12.22)\end{array}$ \\
\hline Expected ambiguity & & $\begin{array}{r}0.0164 \\
(8.17)\end{array}$ & $\begin{array}{c}0.0208 \\
(10.18)\end{array}$ & $\begin{array}{c}0.0238 \\
(11.75)\end{array}$ & $\begin{array}{r}0.0199 \\
(9.79)\end{array}$ & $\begin{array}{r}0.0126 \\
(5.31)\end{array}$ & $\begin{array}{r}0.0141 \\
(6.07)\end{array}$ & $\begin{array}{r}0.0141 \\
(6.04)\end{array}$ \\
\hline Vesting month indicator & & & & $\begin{array}{r}0.0542 \\
(71.21)\end{array}$ & $\begin{array}{l}0.0522 \\
(68.51)\end{array}$ & $\begin{array}{l}0.0445 \\
(58.44)\end{array}$ & $\begin{array}{l}0.0324 \\
(42.79)\end{array}$ & $\begin{array}{l}0.0321 \\
(42.32)\end{array}$ \\
\hline $\log (1+$ months to expiration $)$ & & & & $\begin{array}{r}-0.0220 \\
(-172.48)\end{array}$ & $\begin{array}{r}-0.0212 \\
(-156.06)\end{array}$ & $\begin{array}{r}-0.0253 \\
(-183.17)\end{array}$ & $\begin{array}{r}-0.0313 \\
(-215.89)\end{array}$ & $\begin{array}{r}-0.0313 \\
(-215.87)\end{array}$ \\
\hline 12-month high price indicator & & & & $\begin{array}{r}0.0042 \\
(9.35)\end{array}$ & $\begin{array}{r}0.0037 \\
(8.15)\end{array}$ & $\begin{array}{r}0.0026 \\
(5.84)\end{array}$ & $\begin{array}{r}0.0012 \\
(2.62)\end{array}$ & $\begin{array}{r}0.0011 \\
(2.55)\end{array}$ \\
\hline $\begin{array}{l}\text { Dividend yield } \\
\times \text { dividend month indicator }\end{array}$ & & & & $\begin{array}{r}0.3194 \\
(6.18)\end{array}$ & $\begin{array}{r}0.2637 \\
(5.11)\end{array}$ & $\begin{array}{r}0.2740 \\
(5.23)\end{array}$ & $\begin{array}{r}0.2637 \\
(5.09)\end{array}$ & $\begin{array}{r}0.2633 \\
(5.08)\end{array}$ \\
\hline $\begin{array}{l}\text { Log (stock price } \\
\text { / exercise price })\end{array}$ & & & & $\begin{array}{l}0.0027 \\
(19.13)\end{array}$ & $\begin{array}{l}0.0022 \\
(15.67)\end{array}$ & $\begin{array}{l}0.0048 \\
(25.53)\end{array}$ & $\begin{array}{r}0.0108 \\
(50.79)\end{array}$ & $\begin{array}{r}0.0109 \\
(50.82)\end{array}$ \\
\hline Year fixed effects & No & No & No & No & Yes & No & No & Yes \\
\hline Firm fixed effects & No & No & No & No & No & Yes & No & Yes \\
\hline Person fixed effects & No & No & No & No & No & No & Yes & Yes \\
\hline Observations & $2,142,732$ & $2,142,732$ & $2,142,732$ & $2,142,732$ & $2,142,732$ & $2,142,732$ & $2,142,732$ & $2,142,732$ \\
\hline$R^{2}$ & 0.00005 & 0.00003 & 0.0001 & 0.016 & 0.020 & 0.032 & 0.060 & 0.060 \\
\hline
\end{tabular}




\section{Table 5 \\ Regression estimates of option exercise timing}

Generalized linear mixed model regression estimates of the percentage of an option award that is exercised in the current month, as a function of lags and changes in the volatility and ambiguity variables. The sample includes 2.14 million monthly observations associated with 63,244 option grants that are exercised by 19,192 employees in 3,006 individual firms between 1996 and 2013, using records from the Thomson Reuters Insiders Data file. For a given option award, the percentage of options exercised is the number exercised in a given month divided by the number of vested options held at the start of the month. Expected volatility, based on CRSP daily stock price records, and expected ambiguity, based on TAQ intra-day stock price records, are calculated according to procedures described in the text. The regression models contain all of the control variables from the model in Table 4 above, and the left column in this table reproduces the estimates from the right column of Table 4 for comparison purposes. $t$-statistics clustered by person, firm, month and year appear in parentheses below each coefficient estimate.
Intercept
0.2646
0.2687
0.2677
0.2657
$(160.88)$
$(163.41)$
$(163.60)$
(177.96)

Expected volatility

$-0.2353$

Expected ambiguity

Expected volatility $t-1$

$-0.2073$

$(-10.79)$

Expected ambiguity $t-1$

0.0049

Expected volatility $t_{-2}$

$-0.1942$

Expected ambiguity $t-2$

0.0066

$\Delta$ Expected volatility

$-0.0009$

$\Delta$ Expected ambiguity

0.0030

(3.72)

Year fixed effects

Firm fixed effects

Person fixed effects

Observations

$R^{2}$

$\begin{array}{rrrr}\text { Yes } & \text { Yes } & \text { Yes } & \text { Yes } \\ \text { Yes } & \text { Yes } & \text { Yes } & \text { Yes } \\ \text { Yes } & \text { Yes } & \text { Yes } & \text { Yes } \\ 2,142,732 & 2,142,732 & 2,142,732 & 2,142,732 \\ 0.060 & 0.060 & 0.060 & 0.060\end{array}$




\section{Table 6}

\section{Regression estimates of option exercise timing}

Generalized linear mixed model regression estimates of the percentage of an option award that is exercised in the current month, for certain subsamples of observations. The full sample includes 2.14 million monthly observations associated with 63,244 option grants that are exercised by 19,192 employees in 3,006 individual firms between 1996 and 2013, using records from the Thomson Reuters Insiders Data file. For a given option award, the percentage of options exercised is the number exercised in a given month divided by the number of vested options held at the start of the month. In the first column, we show estimates only for those executives identified as chief executive officers in the Thomson Reuters database. In the middle column, we restrict the analysis to those observations in the top quartile of the volatility variable. In the right column, we restrict the estimation to those observations in the top quartile of the ambiguity variable. Expected volatility, based on CRSP daily stock price records, and expected ambiguity, based on TAQ intra-day stock price records, are calculated according to procedures described in the text. The regression models contain all of the control variables from the model in Table 4 above. $t$-statistics clustered by person, firm, month and year appear in parentheses below each coefficient estimate.

$\begin{array}{lrrr}\text { Subsample } & \begin{array}{r}\text { CEOs } \\ \text { only }\end{array} & \begin{array}{r}25 \% \text { highest } \\ \text { volatility }\end{array} & \begin{array}{r}25 \% \text { highest } \\ \text { ambiguity }\end{array} \\ \text { Intercept } & \begin{array}{r}0.2535 \\ (67.60)\end{array} & \begin{array}{r}0.2681 \\ (82.37)\end{array} & \begin{array}{r}0.2576 \\ \end{array} \\ & & & \\ & -0.1275 .31) \\ \text { Expected volatility } & (-2.86) & -0.0825 & -0.1854 \\ & & (-2.79) & (-5.13) \\ & 0.0146 & 0.0110 & 0.0146 \\ \text { Expected ambiguity } & (2.63) & (2.47) & (3.01) \\ & & & \\ & \text { Yes } & \text { Yes } & \text { Yes } \\ \text { Year fixed effects } & \text { Yes } & \text { Yes } & \text { Yes } \\ \text { Firm fixed effects } & \text { Yes } & \text { Yes } & \text { Yes } \\ \text { Person fixed effects } & 353,556 & 535,684 & 535,684 \\ \text { Observations } & 0.055 & 0.073 & 0.064 \\ R^{2} & & & \end{array}$

